\title{
GEREJA SETAN DAN PROPAGANDANYA DALAM DUNIA HIBURAN
}

\author{
Faidillah Rijani \\ Alumni Jurusan Perbandingan Agama Fakultas Ushuluddin dan Humaniora \\ IAIN Antasari Banjarmasin
}

\begin{abstract}
The movement of Satanism or the so-called Church of Satan appears in America, but it is generally unknown in the Muslim world, especially Indonesia. This article tries to understand the Church of Satan, its ritual and propaganda. This church was established by Anton Szandor Lavey. It is a kind of occultist movement. The ritual of the Church of Satan is based on its 'scripture' called The Satanic Bible. In the ritual, names of satan are recited and adorned, and sexual intercourses among the participants are common. The Church of Satan uses film, music, and electronic games to propagate itself.
\end{abstract}

Kata kunci: gereja setan, propaganda, dunia hiburan

\section{Pendahuluan}

Penelitian ini berlatar belakang tentang banyaknya penistaan terhadap Agama Kristen, salah satunya munculnya Gereja Setan. Penelitian ini bertujuan untuk mengetahui perkembangan Gereja Setan yang awal mulanya hanya sebuah ideologi Satanisme yang dikembangkan oleh Aleister Crowley hingga sekarang lebih terstruktur yang dipimpin oleh Magus Peter H. Gilmore dan tentang beberapa propaganda mereka dari dunia musik, perfilman serta game-game virtual.

Penelitian ini merupakan penelitian kepustakaan (library research) dengan meneliti referensi yang terkait dengan Gereja Setan, baik itu berupa kitab sucinya yaitu The Satanic Bible dan The Satanic Ritual yang mana kitab itu didapatkan dari situs kumpulan buku-buku sihir yaitu darkbook.org, situs/website resmi Gereja Setan http://www.churchofsatan.com, dan beberapa dokumenter tentang Gereja Setan yang diambil dari http:// www.youtube.com untuk lirik lagu dari musik yang beraliran satanis semuanya diambil dari situs bttp://www.dark.lyrics.com dan untuk game/permainan diambil dari situs propaganda Gereja Setan itu sendiri yaitu http:// www.modernchurchofsatan.com, sedangkan untuk refrensi penunjang diambil dari buku Sejarah Setan yang ditulis oleh Hanu Lingga.

Hasil dari penelitian ini yang didapat adalah bahwa Gereja Setan bukanlah sebuah gereja pada umumnya, melainkan sebuah sekte yang mereka namakan sebuah gereja dan itu lahir didasari atas ketidakpuasan mereka terhadap Gereja-gereja Kristen, semua hal yang berbentuk dosa bagi Gereja Kristen, misalkan seks dan obat-obatan menurut mereka adalah jalur untuk menyerang secara ekstrem terhadap sebuah rohani dalam Gereja Kristen. Hal ini, membuat sebuah pergolakan antara iman Kristen dan Satanisme, untuk melancarkan propaganda Gereja Setan memakai aspek dunia hiburan karena mereka bisa mengambil hasil keuntungan royalti dari masyarakat Barat, karena pada umumnya masyarakat Barat sering diwarnai dengan pola kehidupan hedonis. 


\section{Gereja Setan}

Zaman sekarang fenomena keagamaan sangat banyak bermunculan. Di antara fenomena tersebut adalah bermunculannya aliran-aliran baru, seperti dalam agama Kristen pada sekitar tahun 1606 muncul Gereja Reformasi Baptis dan dalam buku Michael Keene ada lagi aliran metodis yang merekan namakan Holy Club (kelompok Suci).

Aliran-aliran baru tersebut sebagian orang menilai karena adanya transformasi global yang tumbuh pada kalangan masyarakat modern sekarang. Karena transformasi global tersebut mempengaruhi agama-agama pada zaman sekarang. Salah satu aliran itu ada pada Gereja Kristen yaitu dengan nama Gereja Setan.

Gereja Setan pertama kalinya didirikan oleh Anton Szandor Lavey dia adalah seorang pemain musik organ pada sebuah karnaval. Anton Sandorz LaVey yang mendirikan Church of Satan (Gereja Setan) pada tanggal 30 April 1966 yang dikenal dengan "Hari Setan" (Walpurgisnacht). Untuk menanamkan keyakinan kepada para pengikutnya, LaVey mengarang beberapa buku di antaranya: The Satanic Bible (1969), The Satanic Ritual (1969). ${ }^{1}$ Anton Szandor Lavey Lahir Dengan Nama Howard Stanton Levey Pada Tanggal 11 April 1930, dan meninggal pada tanggal 29 Oktober 1997 karena penyakit paru-paru di rumah sakit Katolik St. Mary Medical Center di San Francisco. ${ }^{2}$

Dalam karya ciptanya Anton Szandor Lavey yang pengantarnya diisi oleh Burton H.Wolfe (penulis buku revolusi seksual The hippies), bahwa Anton Szandor Lavey telah mendedikasikan dirinya untuk penyembahan terhadap setan. Yang mana hal tersebut sebelumnya berlatarkan tentang penghujatan terhadap Gereja Kristiani.Lavey secara terang-terangan mengundang para wartawan untuk meliput tentang ritualnya. Dari ritual pernikahan, pembaptisan, dan pemakaman kematian yang seluruhnya dipersembahkan atau didedikasikan untuk setan. Untuk melakukan semua ritual tersebut Anton Szandor Lavey pada mulanya melakukan ritual tersebut disekitaran rumahnya tepatnya di lingkungan daerah San Fransisco di sepanjang daerah yang dinamakan Golden Gate. ${ }^{3}$

Burton H. Wolfe dalam tulisan pengantarnya untuk The Satanic Bible, walaupun Sang Anton kecil yang pada saat berumur 18 tahun dia sudah mempunyai arah pemikiran terhadap antitesis sistem kepercayaan Kristen maupun Yahudi. Karena agama yang mempunyai sistem Satanisme adalah agama yang lebih dahulu/lebih tua daripada agama Kristen maupun Yahudi. Namun pemikiran Satanisme yang menurutnya lebih tua tersebut tidak pernah dijadikan sebuah agama resmi pada zaman modern sekarang. ${ }^{4}$

Gereja Setan juga mempunyai jaringan situs resmi yang mempunyai alamat $\underline{\text { http:// }}$ www.churchofsatan.com yang mana isinya kita mampu mengakses informasi yang terkait dengan gereja setan tersebut.

${ }^{1}$ Hanu Lingga, Sejarah Setan: Membongkar Sepak Terjang Setan dan Aliran-aliran Pemuja Setan, cet. 1, (Yogyakarta: Navila Idea, 2011), h. 75-77.

${ }^{2}$ https:// en.wikipedia.org/wiki/ Anton LaVey\#Biography. Diakses pada tanggal 29 Januari 2013 jam 14.43 wita

${ }^{3}$ Anton Szandor Lavey, The Satanic Bible Underground Version, (San Fransisco: 2007), h. 9.

${ }^{4}$ Anton Szandor Lavey, The Satanic Bible Underground Version, h.9-10, satanisme dianggap mereka adalah agama paling tua diantara agama-agama lainnya. Dan mereka mengganggap bahwasanya segala bentuk pemujaan adalah pemujaan terhadap setan. 
Dalam gereja setan kita akan menemukan sebuah struktur keorganisasian dalam yang disusun oleh Anton Szandor Lavey. Dalam situs website aslinya Gereja Setan disebutkan ada lima tingkatan setelah menjadi anggota. Untuk menjadi anggota diharuskan mengisi formulir pendaftaran serta membayar sebesar 200 USD(sekitar 2.000.000 rupiah).

Setelah menjadi anggota aktif, anggota akan mendapatkan sebuah kartu anggota (ID card) dan kitab suci mereka The Satanic Bible dan The Satanic Ritual.

Untuk tingkatan selama menjadi anggota Gereja setan adalah sebagai berikut:

1. Registered Member (No Degree) $\rightarrow \rightarrow \rightarrow \rightarrow \rightarrow \rightarrow \rightarrow$ (orang yang terdaftar)

2. Active Member - Satanist (First Degree) $\rightarrow \rightarrow \rightarrow \rightarrow \rightarrow$ (telah menjadi anggota)

3. Witch/Warlock (Second Degree) $\rightarrow \rightarrow \rightarrow \rightarrow \rightarrow \rightarrow \rightarrow$ (menjadi penyihir)

4. Priestess/Priest (Third Degree) $\rightarrow \rightarrow \rightarrow \rightarrow \rightarrow \rightarrow \rightarrow$ (menjadi pendeta)

5. Magistra/Magister (Fourth Degree) $\rightarrow \rightarrow \rightarrow \rightarrow \rightarrow \rightarrow \rightarrow$ (menjadi magister)

6. Maga/Magus (Fifth Degree) $\rightarrow \rightarrow \rightarrow \rightarrow \rightarrow \rightarrow \rightarrow \rightarrow$ (menjadi magus)

Gerakan Satanisme dikenal sebagai gerakan yang selalu mendambakan akan pesona dunia hiburan, banyak propaganda yang dimasukan lewat berbagai media hiburan misalnya aliran musik, film layar lebar, majalah dan yang lainnya, sebagaimana yang telah di ungkapkan oleh LaVey bahwa: "Satanis menggunakan musik sebagai senjata propaganda untuk mempengaruhi generasi muda di seluruh dunia, untuk menentang Yesus, dengan tujuan untuk mendirikan kerajaan Antichrist di dunia". 5

Salah bagian Propaganda yang dimasukan dalam perfilman, Anton Szandor Lavey ikut terlibat dalam pembuatan film Rosemary Baby 1968, The Devils Rain 1975, dan TheDevil's Mass 1965. Dia terlibat baik secara langsung maupun tidak secara langsung dalam film-film tersebut. ${ }^{6}$

\section{Simbol-Simbol}

Setiap organisasi pasti mempunyai simbol yang ditampilkan kepada orang-orang. Arti simbol tersebut dijadikan sebuah identitas dan sarana komunikasi bagi yang mempunyai simbol tersebut.Apalagi organisasi keagamaan atau gerakan keagamaan banyak mempunyai dasar filosofis mendalam yang ditampilkan dengan simbol-simbol mereka. ${ }^{7}$

Begitu juga dengan gerakan satanisme ini, ada bermacam-macam simbol. Di berbagai media kita dapat mengetahui apa saja simbol Gerakan Satanisme. Biasanya simbol-simbol ini kegunaannya ada untuk ritual, untuk dijadikan lambang organisasinya, dan juga untuk dipopulerkan dan dijadikan pertentangan bagi kaum agamawan khususnya Kristen.

1. Pentagram/Sigil of Baphomet, lambang pentagram kita sering jumpai dalam berbagai film berbau mistik, misalnya film Supranatural, dan dalam film The Covenant, dan film-film berbau mistik lainnya. Karena pentagram ini sudah menjadi ciri khas yang berhubungan dengan sesuatu hal yang erat kaitannya dengan ilmu gaib/okultis di dunia Barat. Dalam The Satanic Bible pentagram disebutkan: The album featured a cover graphic named by LaVey as the "Sigil of Baphomet": the goat head in a pentagram, circled with the Hebrew word "Leviathan," which has since

${ }^{5}$ Karkoons film (dokumenter), Satanisme Kebudayaan Modern, bag. ketiga.

${ }^{6}$ http:/ / wnw.churchofsatan.com/Pages/LaVeyBiography.html, Diakses pada tanggal 1 Mei 2013. Lavey di sini memerankan film The Devil's Mass selain film-film tersebut Lavey hanya menjadi tokoh di belakang layar saja.

${ }^{7}$ F.W. Dilistone, The Power of Symbols, (Yogyakarta: Kanisius, 2002), h.15. 
become the ubiquitous symbol of Satanism. (Album ini menampilkan gambar penutup dinamai oleh LaVey sebagai "Sigil dari Baphomet”: kepala kambing di pentagram, dilingkari dengan kata Ibrani" Leviathan," yang sejak itu menjadi simbol di mana-mana dari Satanism). ${ }^{8}$

2. Satanic Cross, simbol ini pada dasarnya dijadikan sebuah pertentangan untuk salib umat kristiani. Simbol ini juga pelengkap dalam sebuah ritual pemujaan bagi kaum Gereja Setan ini.

3. 666, Simbol ini Lambang 666 diartikan DIC LVX dibaca menjadi “Dicit Lux" dan apabila diterjemahkan dalam bahasa Indonesia bermakna "suara Cahaya" yang mana nama tersebut dikatakan adalah sama dengan nama Lucifer "Lux Ferre" yang bermakna sang pembawa cahaya. Dalam angka Romawi $666=$ DCLXVI, sedangkan dalam bahasa Yunani $666=X s "$ (Chi, Xi, Sigma) atau bisa disebut XES dalam artian umum disamakan dengan SEX.

4. Ular/serpent, simbol ini dalam Gereja Setan disebut juga dengan makna Leviathan (sang penguasa lautan). Oleh karena itu ular sering kali dijadikan ritual dalam gereja Setan. Dalam kitab Satanic Bible di sebutkan :'Leviathan" the serpent of the watery abyss, and identified with Satan. ("Leviathan" adalah ular dalam jurang air yang dalam, dan diidentitaskan sebagai setan).$^{10}$

5. Versace dalam bukunya Ferdi Godjali yang isinya tentang pengusiran setan, lambang Versace disamakan dengan wajah Lucifer berikut kisah yang dipaparkannya:

Pada siang hari, saat saya sedang berkendara dan mendengar lagu puji-pujian, tiba-tiba semua suara berhenti dan saya hanya mendengar satu suara.Ia berbisik dengan sangat lembut dan berkata: "Anak-Ku, lihatlah mobil di depanmu". Kemudian saya membuka dialog dengan Roh Kudus, "Ada Apa Tuhanku?" Tuhan menjawab "Lihatlah stikernya."”Itu gambar merk Versace, Tuhan," sahut saya. Hal yang mencengangkan Tuhan berkata, "Itu wajah Lucifer yang dijadikan merk dagang." Ketika mendengarkan hal itu saya langsung menyampaikan kepada semua orang yang saya layani. Gambar di Versace adalah gambar Medusa yang disetarakan dengan Lucifer. ${ }^{11}$

6. Yang terakhir Simbol lightning bolt yang digabung dengan pentagram, dalam situs resminya di sebutkan bahwa simbol ini sering di pakai oleh Anton Szandor Lavey, dan memang dirancang untuk dibuat liontin. Simbol ini juga menjadi lambang kantor imam besar Gereja Setan pada tahun1970. ${ }^{12}$ Pada saat ini simbol tersebut banyak digunakan sebagai merchandise dalam produk yang dijual untuk kalangan penganut Gereja Setan tersebut.

\section{Tuhan Utama}

Sebelum memasuki ritual, Kita akan mengenal dahulu sisi daripada Setan yang di puja oleh gerakan satanisme ini disebutkan dalam kitab The Satanic Bible ini, dalam nama-nama populer setan yang mereka puja disebut dengan Lucifer/baphomet/azazel.

\footnotetext{
${ }^{8}$ Anton Szandor Lavey, The Satanic Bible Underground Version, h. 28.

${ }^{9}$ Hanu Lingga, Sejarah Setan: Membongkar Sepak Terjang Setan dan Aliran-aliran Pemuja Setan, h. 30-32.

${ }^{10}$ Anton Szandor Lavey, The Satanic Bible Underground Version, h. 53.

${ }^{11}$ Ferdi Godjali, Menghancurkan Kerajaan Iblis dalam Diri Kita, (Yogyakarta: Penerbit ANDI, 2011), h. 215.

${ }^{12}$ http:// wmw.churchofsatan.com/Pages/AntonLaVey Sigil.html, diakses tanggal 9 Mei 2013.
} 
Dalam Bahasa Latin Lucifer dipecahkan dalam tiga kata lux/luccis dan Ferre yang bermakna "pembawa cahaya"13 dalam Alkitab di sebutkan dengan "bintang fajar" atau juga di sebut dengan putra fajar.

Wab, engkau sudah jatuh dari langit, hai Bintang Timur, putera Fajar, engkau sudah dipecabkan dan jatuh ke bumi, hai yang mengalabkan bangsa-bangsa!"(yesaya 14: 12)14

Lucifer digambarkan seperti berkepala kambing bertanduk atau dikenal dengan kambing "Mendes", lambang kuno untuk Setan. Di belakang gambar Lucifer tepatnya terdapat lambang sebuah pentagram. ${ }^{15}$

\section{Tipe-Tipe Ritual Gereja Setan}

Setelah kita membahas tentang siapa yang disebut Lucifer/baphomet yang menurut mereka adalah Setan yang disembah. Sekarang kita membahas tentang beberapa tipe ritual pemujaan yang mereka lakukan. Dalam kitab Satanic Bible tepatnya di bagian Earth Book of Belial disana disebutkan bahwa ada tiga tipe ritual terhadap setan.

a. Ritual Seks: Hubungan Seks yang dilakukan atas nama Setan yang menjadikan sebuah pemujaan terhadap setan. Karena seks menurut mereka adalah jalan menuju kebahagiaan. Dengan digabungkannya antara seks dengan ritual pemujaan, maka hal tersebut menjadikan lebih bermakna.

b. Ritual Cinta Kasih: Ritual yang mengedepankan hal yang berbentuk rasa syukur terhadap apa yang sudah kita berikan dengan orang lain (sebuah pengorbanan).

c. Ritual Kehancuran: sebuah ritual kutukan yang dilakukan atas dasar marah, dendam, dan sebagainya. Hal ini merupakan ritual pembalasan yang dilakukan dengan gabungan antara rasa kehancuran dengan ritual sihir.

Tiga ritual di atas adalah tipe ritual yang bersifat kecil, yaitu ritual yang bisa dilakukan sendiri maupun dengan orang banyak, sedangkan untuk ritual besarnya (ritual yang bisa dilakukan hanya dengan orang yang lebih dari satu) banyak di temukan dalam The Satanic Rituals. Di antara ritual yang sering mereka gunakan ada dua yaitu Le Messe Noir dan The Satanic Baptisms.

\section{Segala Aspek Propaganda}

\section{Musik}

Dunia musik sendiri kita telah mengetahui bahwa Anton Szandor Lavey adalah seorang ahli piano dan dulu ia bekerja pada dunia karnaval. Anton Szandor Lavey, dalam bukunya The Devil Notebook mengungkapkan:

"Music is the most effective tool for evocation". ${ }^{16}$ Maksudnya Musik adalah alat yang paling efektif untuk pembangkitan.

Ada beberapa para musisi yang mengikuti sisi Satanismenya Anton Szandor Lavey di antaranya adalah:

\footnotetext{
${ }^{13}$ http:// id.wikipedia.org/wiki/Lucifer, di akses tanggal 22 april 2013 jam 10.41.

${ }^{14}$ Perjanjian Baru (New Testament), (Jakarta: Lembaga Alkitab Indonesia, 1993) Cet II h.759.

${ }^{15}$ Lucifer dalam pengertian mereka masih mempunyai nama lain yaitu baphomet.

${ }^{16}$ Anton Szandor Lavey, The Devil's Notebook, (United States: Feral House, 1992), h. 26.
} 
a. Marilyn Manson

Dia juga termasuk anggota pada Gereja Setan yang didirikan oleh Anton Szandor Lavey. Ada kartu anggota yang bertuliskan Marilyn Manson. Untuk lebih jelasnya kita bisa melihat foto Marilyn manson bersama Anton Szandor lavey yang diambil pada tahun 1994.

b. Acheron Band

Band ini didirikan pada tahun 1988 di Pittsburgh, Pennsylvania oleh vokalis dan sekaligus penulis lagu yang bernama Vincent Crowley. Pada album pertama berjudul "Messe Noir" yang pada awal lagu tersebut ada diisi oleh Peter H. Gilmore (imam Gereja Setan saat ini).Band ini bergenre black metal seperti Marilyn Manson. Anggota dari Band ini antara lainVincent Crowley sebagai Bassist dan Vokalis, Kyle Severn sebagai pemain Drum, Max Otworth sebagai pemetik Gitar. ${ }^{17}$

\section{Propaganda perfilman}

Selain dalam dunia musik gerakan satanisme juga aktif dalam dunia perfilman di antaranya film Rosemary Baby (1968), dan film The Devil's Rain (1975). ${ }^{18}$

1. Rosemary Baby (1968)

Film ini diambil dari sebuah novel berjudul sama Rosemary Baby karya Ira Levin pada tahun 1967. Film ini disutradai oleh Roman Polanski dan menghabiskan dana produksi sebesar $\$ 2.300 .000$. Film ini menceritakan tentang seseorang wanita yang bernama Rosemary Woodhouse diperankan oleh Mia Farrow yang mengandung bayi atas persetubuhannya dengan Setan. ${ }^{19}$

2. The Devil's Rain (1975)

Film ini mengisahkan tentang kutukan yang terjadi di keluarga Mark Preston (William Shatner), yang mana keluarga tersebut mengkhianati imam gereja Setan yaitu Jonathan Corbis (Ernest Borgnine). Dalam film ini Anton Szandor Lavey juga ikut berperan sebagai Imam besar dari gereja setan sekaligus sebagai penasihat dari film tersebut.

Film ini mendapat kritikan negatif, salah satunya adalah kritikan dari Michael Adams seorang pemerhati film asal Australia mengatakan "It's about a cult, has a cult following, was devised with input from a cult leader, and saw a future superstarindoctrinated into a cult he'd help popularize". (ini adalah tentang kultus, yang telah diikuti pemujaan, dirancang dengan masukan dari seorang pemimpin sekte, dan melihat superstar masa depan yang diindoktrinasi ke kultus untuk membantu mempopulerkan sekte tersebut). ${ }^{20}$

\section{Propaganda Dalam Game Virtual}

Untuk masalah propaganda gerakan Satanisme dalam dunia game, didalam situs resmi www.modernchurchofsatan.com banyak game-game populer beredar dengan aliran satanismenya sangat kental di dalamnya diantaranya adalah Bible Fight, Silent Hill 3, dan Escape From Hell.

\footnotetext{
${ }^{17}$ http:/ / en.wikipedia.org/wiki/ Acheron band, Diakses pada tanggal 20 mei 2013 jam 14.45 wita.

${ }^{18}$ Anton Szandor Lavey, The Satanic Bible Underground Version, h..29.

${ }^{19}$ http:/ / en.wikipedia.org/wiki/Rosemary Baby film, diakses pada tanggal 29 Mei 2013 pada jam 14.00.

${ }^{20}$ http:// en.wikipedia.org/wiki/The Devil Rain, diakses pada tanggal 29 Mei 2013 pada jam 14.00.
} 
1. Bible Fight

Game ini adalah keluaran 2K dan untuk memainkannya dengan memakai game X-BOX 360, jenis game ini adalah Head To Head (satu lawan satu). Unsur satanisme dalam game ini adalah Setan yang bertarung melawan para kelompok Nabi. Game ini memakai sesuai urutan Nabi yang pertama yaitu Adam dan Hawa, Noah, Moses, Mary Magdalena dan Jesus.

2. Escape From Hell

Game yang di keluarkan oleh Addicting. Games ini mempunyai tema tentang bagaimana cara keluar dari neraka dengan memakai mobil yang telah di beri azimat pentagram di sekitarnya.

3. Silent Hill 3

Game ini diproduksi oleh Konami untuk Playstation 2. Game ini mengisahkan petualangan oleh Heater Mason untuk melawan para sekte pemuja Setan yang dinamai The Halo Of the Sun dengan pimpinan sekte Claudia. ${ }^{21}$ Namun dibalik The Halo Of the Sun ada tampilan gambar berupa Baphomet. Hal itu kelihatan jelas ketika Heater Mengambil buku Ancient God diperpustakaan.

\section{Analisis Dan Hasil}

Kajian sosiologi agama banyak berbicara tentang gerakan keagamaan/gerakan spiritual. Dalam buku kajian sosiologi agama karangan Betty R Scharf yang mengambil dari teori Ernest Troeltsch mengatakan:

"Gereja adalah suatu lembaga yang terorganisir besar (dengan struktur yang jelas) dan bersifat keterbukaan, pelayanan yang teratur dengan waktu telah di tentukan. Dan dia lahir dari hasil kerja penebusan dosa." Sedangkan "sekte adalah kelompok yang terbentuk dari masyarakat sukarela yang bentuknya agak sedikit dan agak tertutup, dan antar sesama penganut masih dalam keterikatan hubungan yang kuat, dan sekte berasal dari masyarakat kelas bawah dan ia tidak punya teologi yang jelas, akan tetapi mempunyai mitos yang kuat dan harapan besar untuk menatap masa depan."22

Dalam buku Elizabeth K. Notthingham menjelaskan tentang denominasi:

"Denominasi/ aliran keagamaan adalah suatu kelompok yang stabil dan letaknya diantara gereja dan sekte dan ia sifatnya tidak terlalu keras dan berat bisa dikatakan ia adalah moderat. Sedangkan Cult/mistisisme hampir sama dengan sekte dan kelompok Cult sering berada dalam kawasan metropolitan. Dan Cult mempunyai kepemimpinan yang kharismatik(seorang tokoh yang diagungkan)"23

Untuk kasus gerakan satanisme yang digerakan oleh Anton Szandor Lavey ini bisa dikatakan jenisnya adalah Sekte ideologi okultisme yang mempunyai organisasi terstruktur dengan anggota

\footnotetext{
${ }^{21}$ http:// silenthill.wikia.com/wiki/Halo of the Sun, diakses pada tanggal 29 mei 2013 pada jam 13.44. 125.

${ }^{22}$ Betty R. Scharf, Kajian Sosiologi Agama, terj. Machnun Husein, (Yogyakarta: PT. Tiara Wacana Yogya, 1995), h. 124-

${ }^{23}$ Elizabeth K. Nothingham, Agama dan Masyarakat, terj. Abdul Muis Naharong, (Jakarta: PT. RajaGrafindo Persada, 1994), h. 165-166.
} 
yang tidak terlalu besar dan pengikutnya sukarela.Serta mereka punya tokoh yang kharismatik yaitu Anton Szandor Lavey Namun kenyataannya mereka menyebutkan adalah Sebuah Gereja.

Dalam perkembangannya dari dulu hingga sekarang mereka mempunyai ideologi yang bedasarkan seksual, itu bisa kita lihat dari tata cara ritual mereka tersebut. Seks yang menurut mereka adalah sebuah hal yang sakral bagi mereka.Dan itu merupakan penghormatan untuk tuhan yang disembah mereka yaitu Baphomet/Lucifer.

Untuk Propaganda dunia musik adalah hal yang berkembang pesat didunia barat, musik yang mengiringi dalam gerakan satanisme ini adalah musik yang beraliran keras, seperti Rock, Black Metal, Death Metal, Punk, Underground dan sebagainya.

Oleh karena itu, musik adalah hal yang sangat mudah didengar oleh anak muda dikalangan barat.Band-Band tersebut menyuarakan lirik lagu yang bernuasa Atheis, seksual, tentang pemujaan terhadap baphomet, Lucifer, tentang AntiGod (Anti Tuhan), dan AntiChrist (Anti Yesus/Kristen). Bukan hanya dari lirik lagu saja yang mereka suarakan, akan tetapi dari sampul album mereka dihiasi hal yang berunsur satanisme tersebut. Sehingga, lama kelamaan musik aliran keras dianggap musik yang menyuarakan tentang Satanisme.Namun, hal tersebut tidak bisa dihentikan karena Negara barat adalah Negara yang bebas dalam berkreasi bidang seni.

Untuk dua film Rosemary Baby dan The Devil's Rain adalah film yang berdasarkan unsur satanisme yang dipadukan dengan aliran horror yang pada waktu itu film horror memang berkembang pesat di Negara barat khususnya New York. Dengan Film-film tersebut Church Of Satan/Gereja Setan bisa menampikan eksistensi satanismenya. Dan fenomena ini hampir sama dengan aliran musik yang banyak mendapatkan kritikan dari pemerhati. Namun hal tersebut tidak bisa dihentikan karena Film adalah Budaya Seni yang bebas berkembang.

Dan dalam Game Virtual Yang kebanyakan peminatnya adalah anak-anak. Hal-hal yang ditampilkan dalam Game tersebut bisa dikatakan adalah sesuatu pengenalan fenomena Satanisme yang diramu dengan tampilan untuk menghibur.

\section{Penutup}

Gerakan Satanisme/Church Of Satan (Gereja Setan) yang di bangun oleh Anton Szandor Lavey adalah gerakan yang berdasarkan dari hal berbau okultisme.

Dalam perkembangannya ajaran satanisme Lavey banyak menggunakan propaganda baik itu dalam Film maupun dalam dunia Musik.

Untuk Ritual Church of Satan hingga saat ini masih menggunakan pedoman dari dua kitab sucinya yaitu The Satanic Bible dan The Satanic Ritual. Karena dua kitab tersebut memang kitab yang dibuat khusus oleh Lavey untuk para pengikutnya agar bisa memahami akan doktrin yang diajarkannya.

Dalam perkembangan organisasinya Gereja Setan menggunakan beberapa tingkatan dari awal mulanya hanya menjadi anggota hingga menjadi para magus (imam besar).Namun untuk menjadi imam tersebut memang harus ditunjuk langsung dari imam sebelumnya.

Propaganda gerakan Satanisme dari dunia musik ini lebih banyak dipopoler oleh BandBand ternama dari berbagai macam belahan dunia, dan hal tersebut bukan hanya untuk dijadikan komersil untuk album-album mereka, akan tetapi memang menjadi dasar aliran mereka yang mempropagandakan tentang aliran satanisme. Sedangkan dalam dua film yang bertemakan 
satanisme memang dijadikan oleh Lavey sebagai ajang untuk memperkenalkan Church of Satan terhadap penontonnya. Dalam dunia Game itu bukan berasal dari Lavey akan tetapi game tersebut memang bernuasa propaganda satanisme yang di perkenalkan oleh salah satu situs Church of Satan yaitu Modern Church Of Satan.

\section{DAFTAR PUSTAKA}

Dilistone, F.W. The Power Of Symbols, Yogyakarta: Kanisius, 2002.

Godjali, Ferdi. Menghancurkan Kerajaan Iblis dalam Diri Kita. Yogyakarta: Penerbit ANDI, 2011. Karkoons film (dokumenter), Satanisme Kebudayaan Modern, bag. ketiga.

Lavey, Anton Szandor, The Devil's Notebook. United States: Feral House, 1992. The Satanic Bible Underground Version. San Fransisco: 2007.

Lembaga Alkitab Indonesia. Perjanjian Baru (New Testament). cet. 2. Jakarta: Lembaga Alkitab Indonesia, 1993.

Lingga, Hanu. Sejarah Setan: Membongkar Sepak Terjang Setan dan Aliran-aliran Pemuja Setan. cet.

1. Yogyakarta: Navila Idea, 2011.

Nothingham, Elizabeth K. Agama dan Masyarakat, terj. Abdul Muis Naharong. Jakarta: PT. RajaGrafindo Persada, 1994.

Scharf, Betty R. Kajian Sosiologi Agama, terj. Machnun Husein. Yogyakarta: PT. Tiara Wacana Yogya, 1995.

bttps:// en.wikipedia.org/wiki/ Anton LaVey\#Biography, diakses pada tanggal 29 Januari 2013 jam 14.43 wita

bttp:// www.churchofsatan.com/Pages/LaVeyBiography.html, diakses pada tanggal 1 Mei 2013. http:// www.churchofsatan.com/Pages/AntonLaVeySigil.html, diakses tanggal 9 Mei 2013. http://id.wikipedia.org/wiki/Lucifer di akses tanggal 22 april 2013 jam 10.41. bttp://en.wikipedia.org/wiki/Acheron band, diakses pada tanggal 20 mei 2013 jam 14.45 wita. bttp://en.wikipedia.org/wiki/Rosemary Baby film, diakses pada tanggal 29 Mei 2013 pada jam 14.00.

bttp:// en.wikipedia.org/wiki/The Devil Rain, diakses pada tanggal 29 Mei 2013 pada jam 14.00. http://silenthill.wikia.com/wiki/Halo of the Sun, diakses pada tanggal 29 mei 2013 pada jam 13.44 . 